\title{
Bioinformatics analysis of genetic variants of endoplasmic reticulum aminopeptidase 1 in ankylosing spondylitis
}

\author{
XIAOLI WANG ${ }^{1}$, JIE MA $^{1}$, JIANBING MA ${ }^{2}$, YURONG WEN ${ }^{3}$, LIESU MENG ${ }^{1}$, HAO YANG $^{4}$, \\ RUI ZHANG ${ }^{1,5}$ and DINGJUN HAO ${ }^{5}$
}

\begin{abstract}
${ }^{1}$ Department of Biochemistry and Molecular Biology, Xi'an Jiaotong University Health Science Center, Xi'an, Shaanxi 710061; ${ }^{2}$ Department of Joint Surgery, Hong Hui Hospital, Xi'an Jiaotong University Health Science Center, Xi'an, Shaanxi 710054; ${ }^{3}$ Center for Translational Medicine, Key Laboratory of Biomedical Information Engineering of Ministry of Education, School of Life Science and Technology, Xi'an Jiaotong University, Xi'an, Shaanxi 710049;

${ }^{4}$ Translational Medicine Center and ${ }^{5}$ Department of Spine Surgery, Hong Hui Hospital, Xi'an Jiaotong University Health Science Center, Xi'an, Shaanxi 710054, P.R. China
\end{abstract}

Received July 22, 2016; Accepted May 4, 2017

DOI: $10.3892 / \mathrm{mmr} .2017 .7417$

\begin{abstract}
According to the results of the first genome-wide association study of ankylosing spondylitis (AS), endoplasmic reticulum aminopeptidase 1 (ERAPl) may serve an important role. However, a number of case-control studies have not been able to replicate this result using the same genetic markers. In the present study, the role of common genetic variants of ERAPl in AS was investigated using two-stage bioinformatics analysis. In the first stage, a classical metaanalysis was performed to assess AS susceptibility markers in ERAP1 using data from available published case-control association studies. The summary odds ratios for 10 single nucleotide polymorphisms (SNPs) were observed to be statistically significant in different studies. In the second stage, the functional effects of these genetic ERAPl variants were investigated using prediction tools and structural analyses. The K528R (rs30187) substitution SNP in ERAP1 was termed as likely damaging by PolyPhen-2 software, was observed to be located close to the entrance of the substrate pocket, and was predicted to contribute to reduced ERAP1 aminopeptidase
\end{abstract}

Correspondence to: Professor Dingjun Hao, Department of Spine Surgery, Hong Hui Hospital, Xi'an Jiaotong University Health Science Center, 555 East Youyi Road, Xi'an, Shaanxi 710054, P.R. China

E-mail: haodingjun@126.com

Dr Rui Zhang, Department of Biochemistry and Molecular Biology, Xi'an Jiaotong University Health Science Center, 76 West Yanta Road, Xi'an, Shaanxi 710061, P.R. China

E-mail: zhangruity12@163.com

Key words: ankylosing spondylitis, endoplasmic reticulum aminopeptidase 1, single nucleotide polymorphism, genetic variation, bioinformatics analysis activity. In addition, the R725Q (rs17482078) SNP, which was an additional potentially damaging substitution, was suggested to decrease the enzymatic activity of ERAP1, as this substitution may lead to the loss of two hydrogen bonds between R725 and D766 and affect the stability of the C-terminus of ERAP1. In conclusion, the results of the two-stage bioinformatics analysis supported the hypothesis that ERAP1 may present an important susceptibility gene for AS. In addition, the results revealed that two functional SNPs (rs30187 and rs17482078) demonstrated the potential to decrease the enzymatic activity of ERAP1 by affecting its protein structure. Further protein structure-guided studies of the specificity and activity of these ERAP1 variants are therefore warranted.

\section{Introduction}

Ankylosing spondylitis (AS), a subtype of spondyloarthritis (Online Mendelian Inheritance in Man, ref no. 106300; https://www.omim.org/entry/106300), is a progressive chronic disease characterized by inflammatory lower back pain, and is occasionally accompanied by peripheral arthritis, enthesis, iritis, spinal deformity and ankyloses $(1,2)$. AS is highly heritable $(>90 \%)$ and demonstrates an estimated prevalence of $0.1-0.4 \%$ in the Caucasian population and $0.2-0.54 \%$ in the Chinese population $(3,4)$.

Previous studies have indicated that AS is strongly associated with the human leukocyte antigen-B27 gene $(3,5)$, a haplotype of the major histocompatibility complex (MHC). However, additional studies have suggested that non-MHC genes may be involved (6-8). Recently, according to the first genome-wide association study of AS in a Caucasian population, endoplasmic reticulum aminopeptidase 1 (ERAPl; also known as ARTS1), located on chromosome 5q15, has been demonstrated to serve an important role in the risk of developing AS (7). Subsequently, a number of European and Asian studies have attempted to replicate this study using different single nucleotide polymorphisms (SNPs), and associations 
have been reported in different populations (1,9-17). However, a number of case-control studies have failed to report this association using the same genetic markers (4,18-20). Potential rationales for these inconsistent results include ethnic differences between populations, the heterogeneity of AS and inadequate statistical power in certain studies. These inconsistencies may be overcome by performing a meta-analysis, which provides a quantitative approach for combining different independent studies and may maximize the overall statistical power $(21,22)$.

There are $>13$ known AS-associated SNPs that span the ERAPl gene locus, including rs3734016, rs26653, rs27895, rs2287987, rs27434, rs30187, rs10050860, rs17482078, rs27044, rs1065407, rs27980, rs7711564 and rs27037, which have been used as genetic markers in multiple association studies (1,7,9-20). A total of 8 SNPs (rs3734016, rs26653, rs27895, rs2287987, rs30187, rs10050860, rs17482078 and rs27044) are non-synonymous substitutions in the coding region of the ERAPl gene, which implies that the corresponding amino acid substitutions exhibit functional effects $(9,11)$.

In the present study, a two-stage bioinformatics analysis was performed in order to investigate the role of common genetic variants of ERAPI in AS. In the first stage, a classical meta-analysis was used to assess all of the AS-associated SNPs in ERAP1, using all published case-control association studies. In the second stage, the functional effects of these genetic variants of ERAPl were investigated using protein structure analysis.

\section{Materials and methods}

Literature search. To identify studies for inclusion in the metaanalysis, PubMed (http://www.ncbi.nlm.nih.gov), Scopus (http://www.scopus.com) and Embase (http://www.elsevier. com/online-tools/embase) citations up to June 2016 were queried with the following search terms: 'ERAP1', 'endoplasmic reticulum aminopeptidase 1', 'ARTS1', 'Ankylosing spondylitis' and 'AS'. The retrieved abstracts were read to identify studies that examined the association between a polymorphism in the ERAPl gene locus and AS. Studies of this type were subsequently read in full to assess their appropriateness for inclusion in the meta-analysis. All references cited in these studies were reviewed to identify additional studies not indexed by PubMed, Scopus and Embase.

Inclusion criteria, exclusion criteria and data extraction. Only studies that tested $\geq 1$ polymorphism within the ERAPI gene locus were included in the current meta-analysis. In addition, studies that met all of the following criteria were included: i) Publication in a peer-reviewed journal; ii) publication in English; iii) presentation of original data on genotype and/or alleles in case and control samples; iv) independence from other studies (i.e. studies that included and re-analyzed a previously published data set were not regarded as independent, and in such cases, only the study that had published the primary data set was included in the meta-analysis); and v) presence of sufficient data to calculate an effect size (23). For each included study, the following data were extracted by two independent investigators using standard forms: First author; journal; year of publication; study design; ethnicity of the subjects; sample size; phenotype information; genotype and allele distribution of subjects with and without AS (24).

Statistical analysis. Population-based studies were collected and subdivided into European and Asian ethnic populations. Data regarding the genotype and/or allele distributions are summarized in Tables I-IV. The genotype and/or allele frequencies in these studies were analyzed using the EpiInfo ${ }^{\mathrm{TM}}$ program version 7.2 (Centers for Disease Control and Prevention, Atlanta, GA, USA; http://www.cdc.gov/epiinfo), and $\mathrm{P}<0.05$ was considered to indicate a statistically significant difference. Prior to the pooling procedure, Cochran's $\chi^{2}$-based Q-statistic, which was considered significant at $\mathrm{P}<0.10$, was performed to assess the heterogeneity within the group of odds ratios (ORs). The extent of the inconsistency across the studies was quantified using the $\mathrm{I}^{2}$ statistic, and $\mathrm{I}^{2}>50 \%$ was considered to be a large heterogeneity value among studies (21). The natural logarithms of the OR estimates were determined using random-effect or fixed-effect models, depending on the heterogeneity among studies. The significance of the pooled ORs was determined using the Z-test. An ancillary procedure for funnel plot asymmetry was additionally used to qualitatively assess the evidence for publication bias. The above statistical analyses were performed using the RevMan software program (version 5.2; http://www.cochrane.org/revman) (22).

Structural and functional analysis. The functional effects of the non-synonymous variants of ERAPl were analyzed using the PolyPhen-2 software program (http://genetics. bwh.harvard.edu/pph2/), which is an automatic tool for predicting the possible effects of an amino acid substitution on the structure and function of a human protein. This prediction is based on a number of features contained in the sequence, as well as phylogenetic and structural information characterizing the substitution (25). Further structural analysis was performed with the molecular visualization software PyMOL (version 1.5.0.4; Schrödinger, Inc., Portland, OR, USA), on the basis of the 2YD0 (http://www.rcsb. org/pdb/explore.do?structureId=2yd0) and 3MDJ (http://www. rcsb.org/pdb/explore/literature.do?structureId=3MDJ) Protein Data Bank (PDB) structures (26).

\section{Results}

Available studies. In total, $\geq 89$ studies were identified by the combined search. The reviews and studies written in languages other than English were excluded, leaving 63 studies. An additional 39 references that did not clearly meet the criteria or were not SNP association studies were further excluded. Therefore, a total of 24 studies remained. Nine additional references were excluded due to the fact that they did not supply the original data regarding genotypes and/or alleles in their samples $(2,8,27-33)$, and one study was excluded due to the analysis of the same samples as previous studies (Table I) (34). Ultimately, a total of 14 studies contributed to available data regarding the following 13 identified SNPs in ERAP1 associated with AS: Rs3734016, rs26653, rs27895, rs2287987, rs27434, rs30187, rs10050860, rs17482078, rs27044, rs1065407, rs27980, rs7711564 and rs27037 (Table II) (1,7,9-20). 


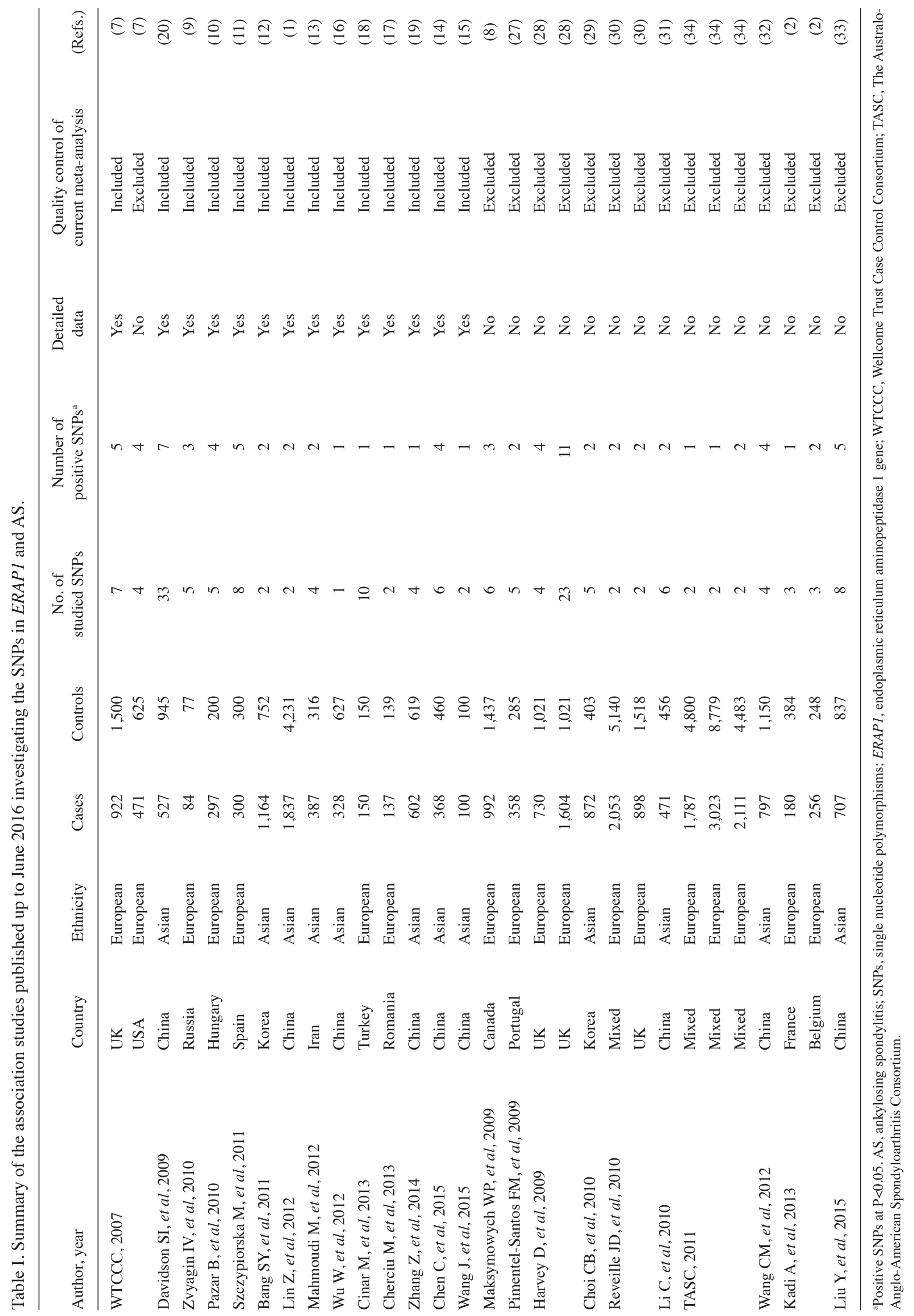




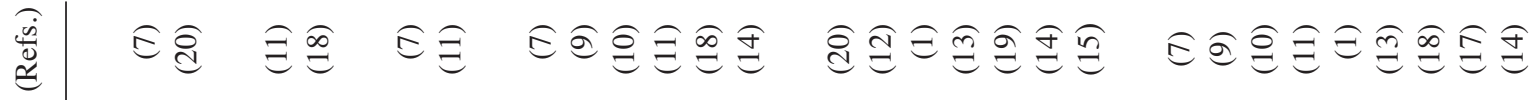

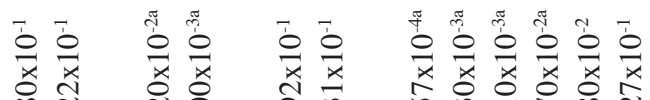

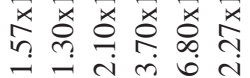

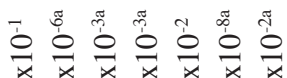

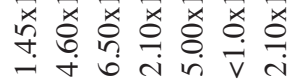

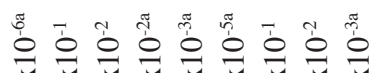

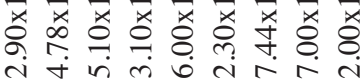

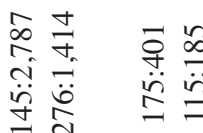

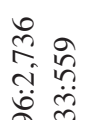

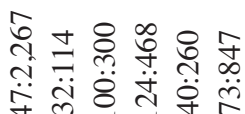

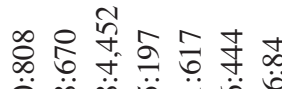

ลू.

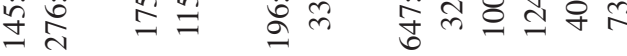

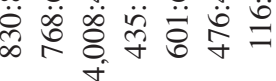

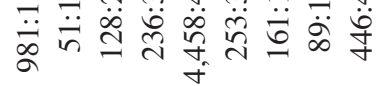

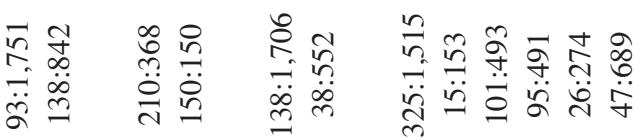

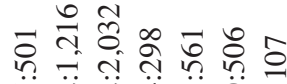

屯융

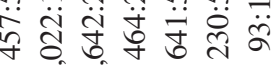

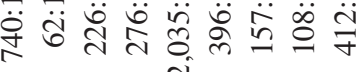

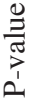

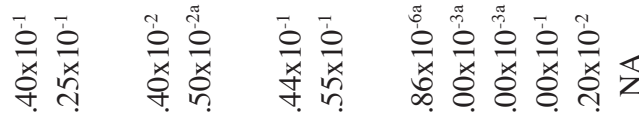

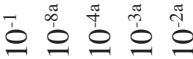

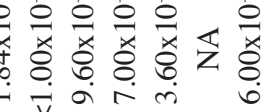

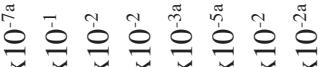

a- $\infty-$

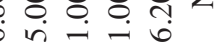

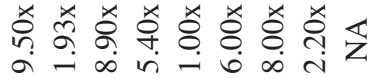

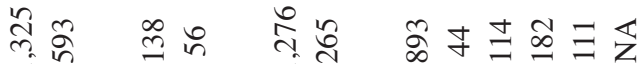

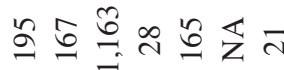

త্రু

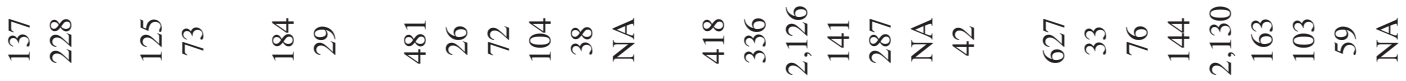

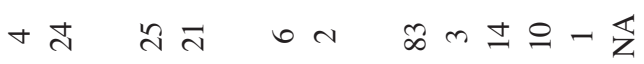

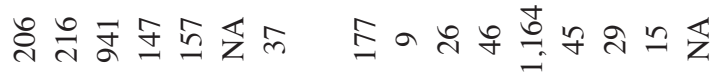

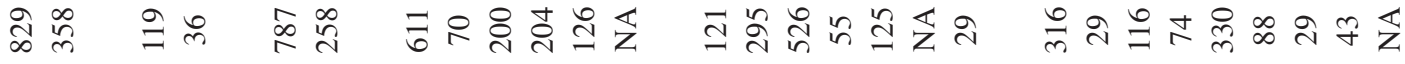

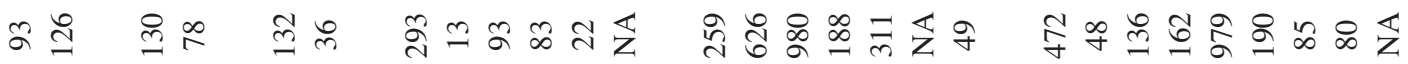

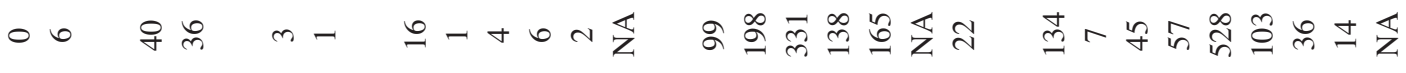

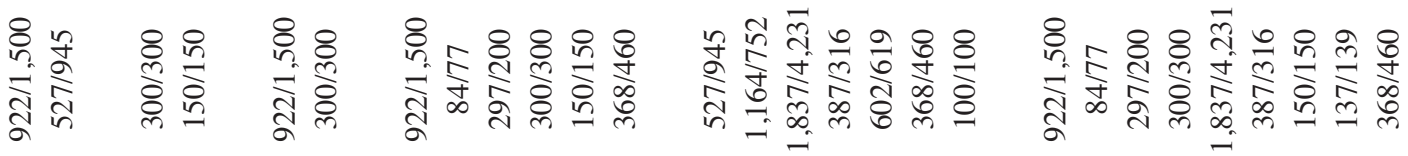

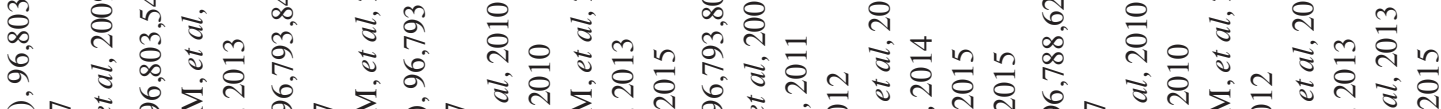

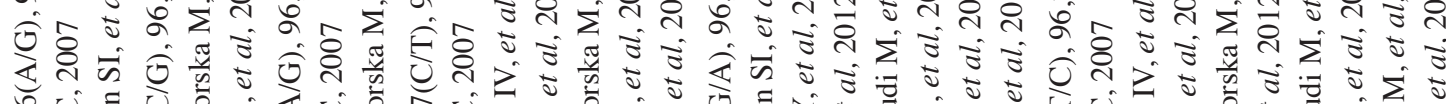

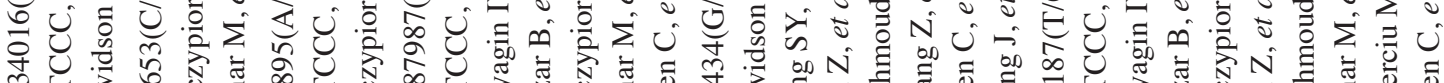

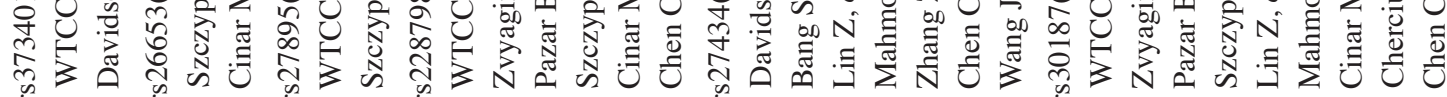




\begin{tabular}{|c|c|c|c|c|c|c|}
\hline $\begin{array}{l}\mathscr{\mathscr { m }} \\
\stackrel{\mathscr{E}}{\mathscr{E}}\end{array}$ & $E \widehat{\subseteq} \widehat{\varrho} \cong \stackrel{\mathscr{D}}{=}$ & 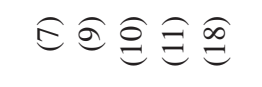 & 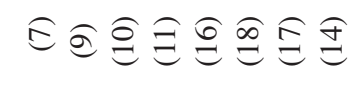 & ટ્d & 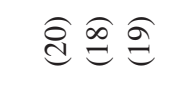 & 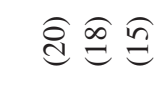 \\
\hline 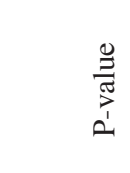 & 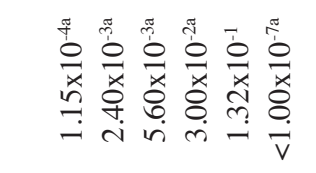 & 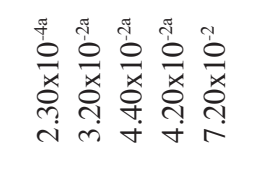 & 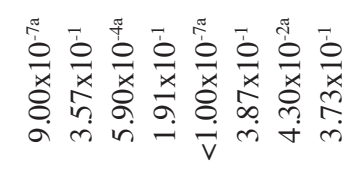 & 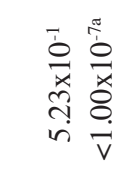 & 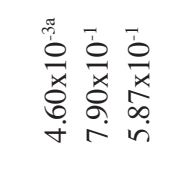 & 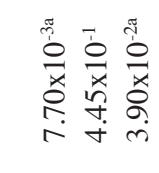 \\
\hline 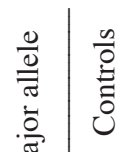 & 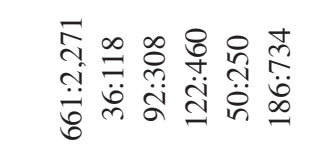 & 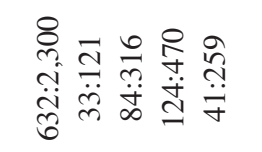 & 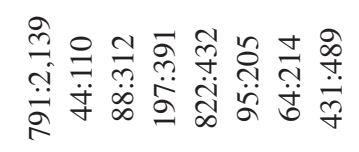 & 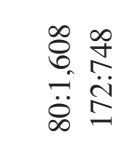 & 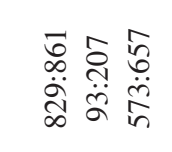 & $\begin{array}{l}\hat{\tilde{n}} \\
\dot{0} \\
\dot{\sim} \\
\infty \\
\infty\end{array}$ \\
\hline 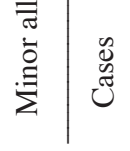 & 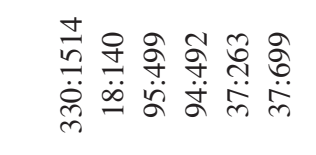 & 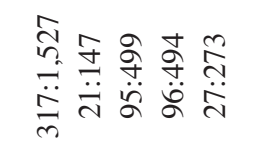 & 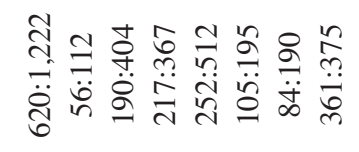 & 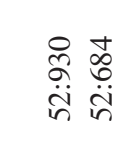 & 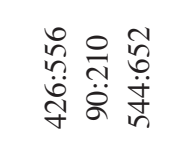 & 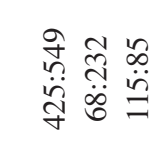 \\
\hline 音 & 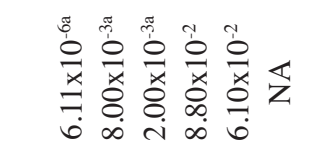 & 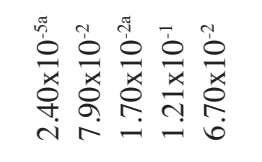 & 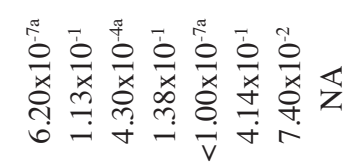 & $\begin{array}{l}\overrightarrow{0} \\
\underset{x}{x} \\
\stackrel{n}{i}\end{array}$ & 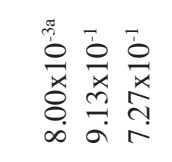 & 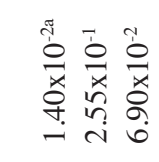 \\
\hline$\tilde{4}$ & 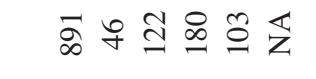 & テัチさे & 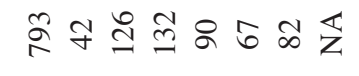 & $\hat{\imath} \mathbb{z}$ & 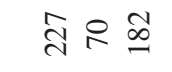 & $\underset{\sim}{\infty} \infty$ \\
\hline$\stackrel{0}{4}_{0}$ & 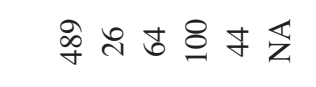 & 字 & 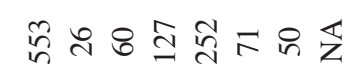 & 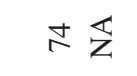 & के ธิ઼ & $\stackrel{q}{q}$ in \\
\hline$\underbrace{\circ}_{0} \mid=$ & $\infty n \pm=n \mathbb{Z}$ & $\stackrel{\infty}{\sim} \cong \simeq$ & 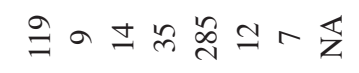 & $n \mathbb{Z}$ & $\exists \cong$ 早 & ڤ્సે 으: \\
\hline ส & 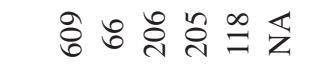 & त్ర & 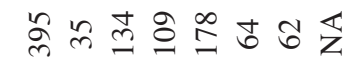 & केष $\mathbb{z}$ & กี & $\stackrel{n}{-} \infty$ \\
\hline 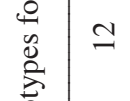 & 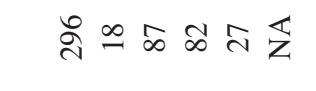 & $\ddot{N}=\infty \infty \approx$ & デ & n $\mathbb{Z}$ & तิ $\infty$ ปे & वे 8 in \\
\hline$=$ & $=0+0$ 的 & $\because a n \wedge d$ & 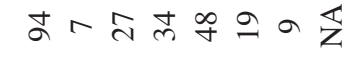 & $\circ \overleftrightarrow{z}$ & $\infty=\mathfrak{a}$ & $\infty+\infty$ \\
\hline 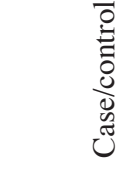 & 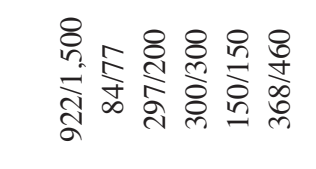 & 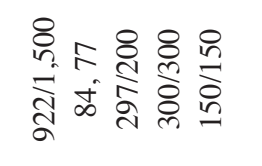 & 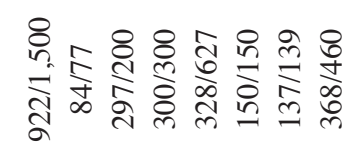 & 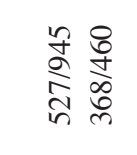 & 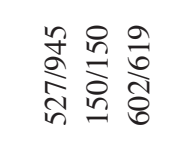 & 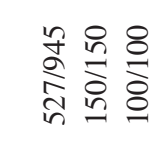 \\
\hline 音 & 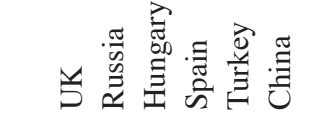 & 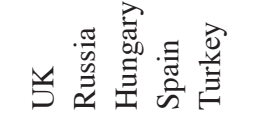 & 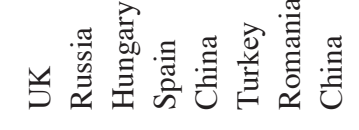 & 竎 & 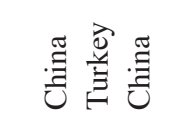 & 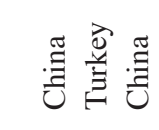 \\
\hline 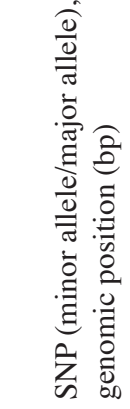 & \multicolumn{6}{|c|}{ 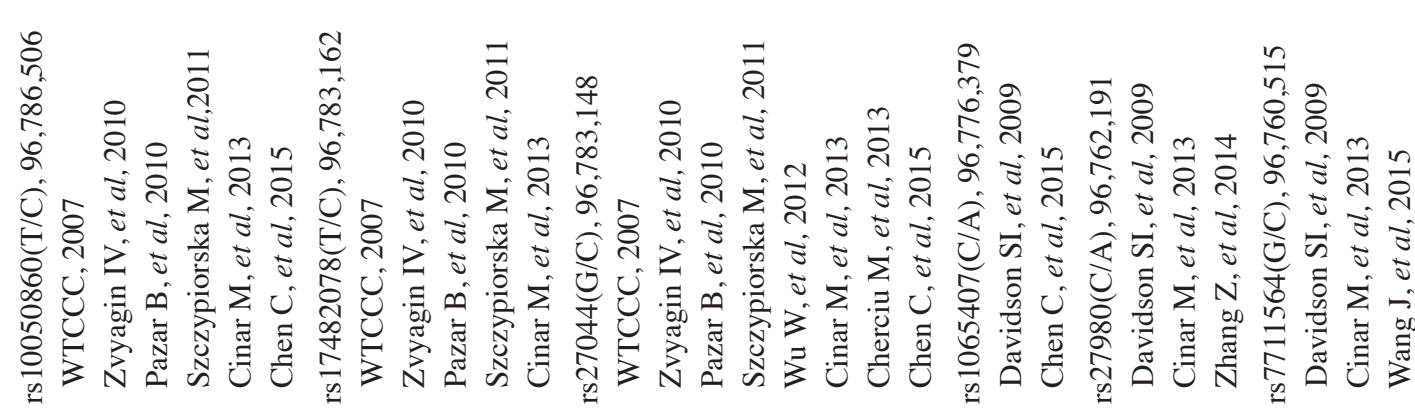 } \\
\hline
\end{tabular}



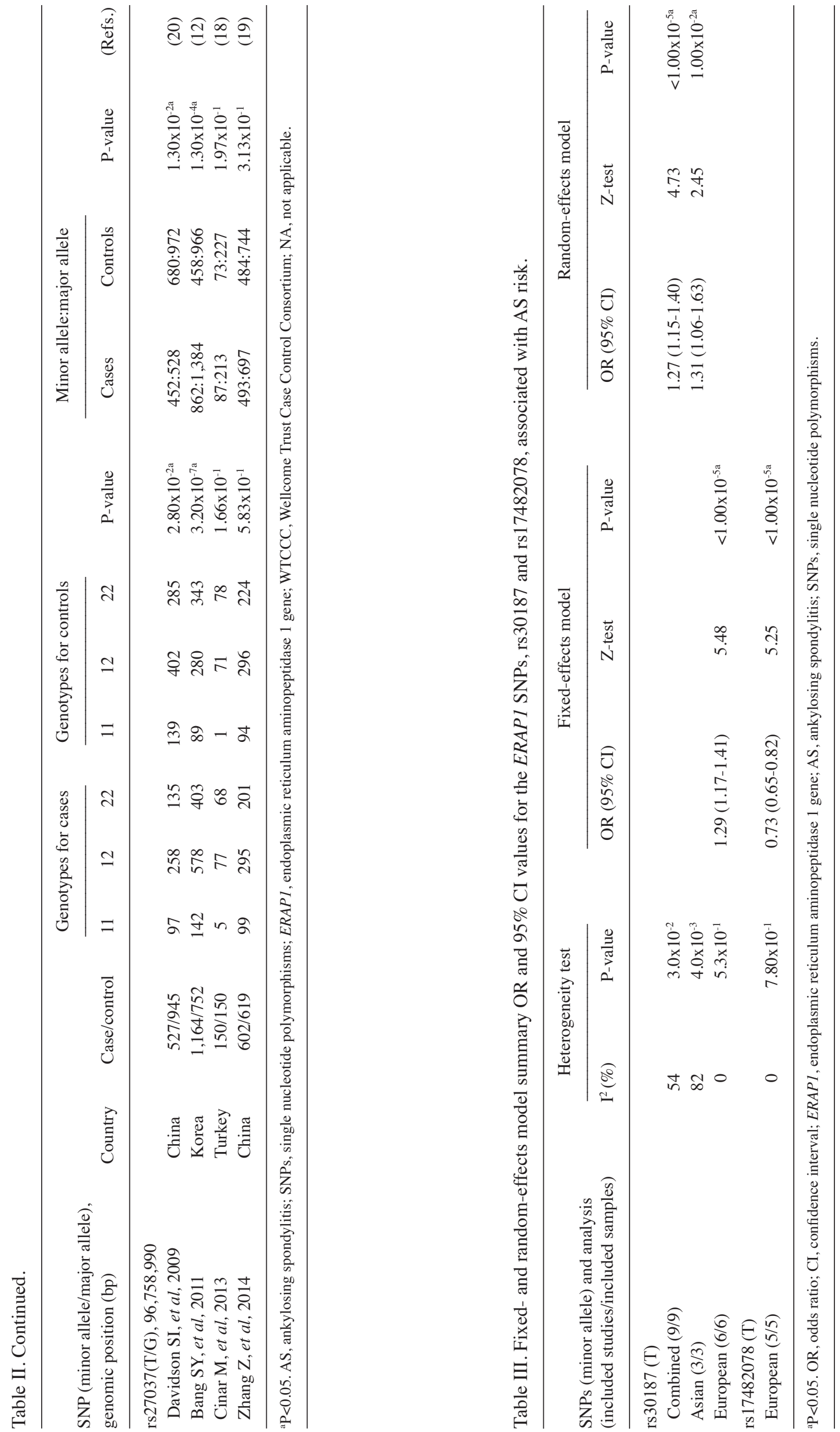


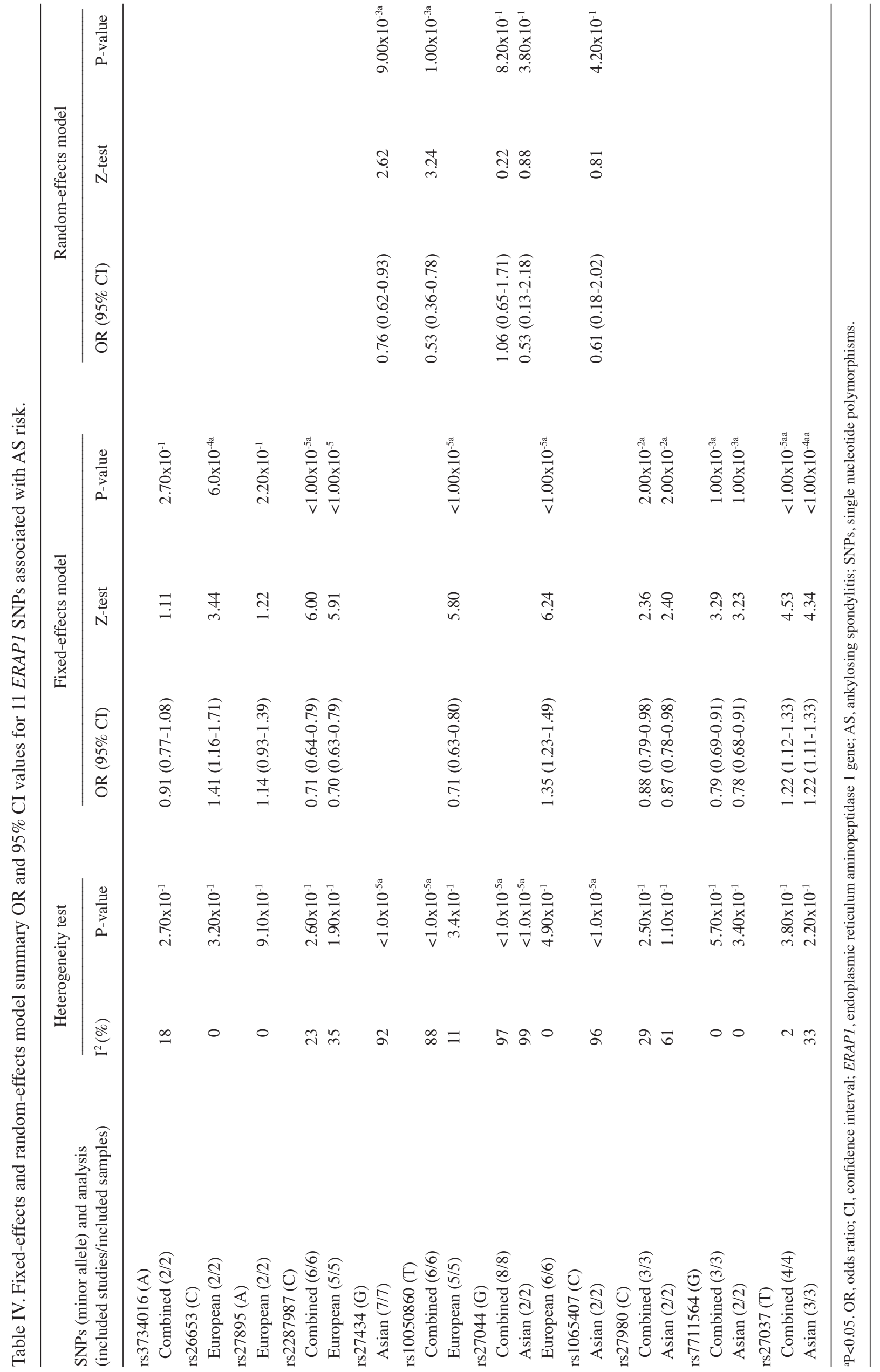



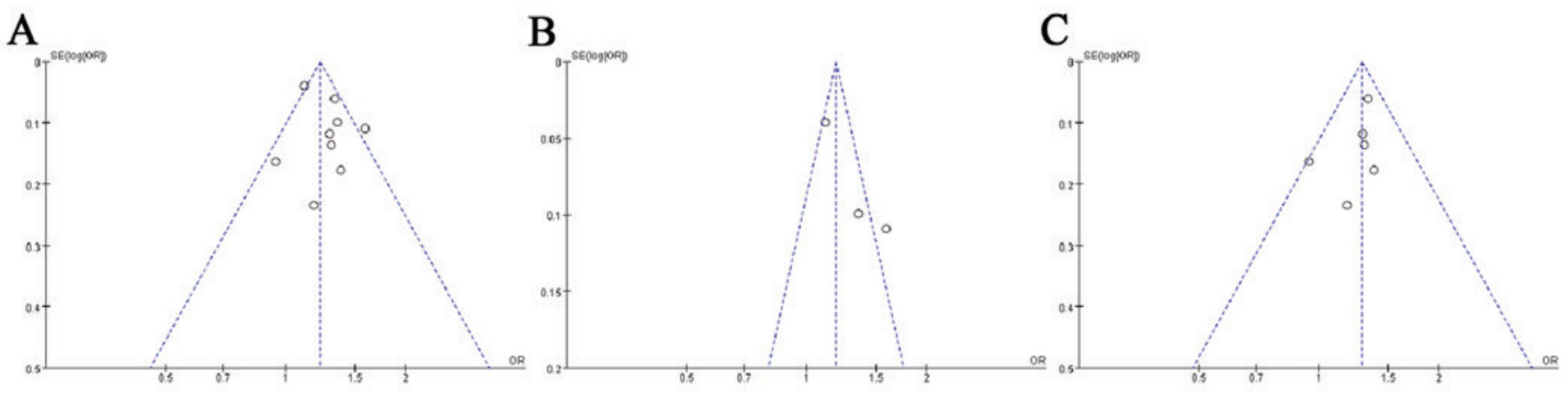

Figure 1. Funnel plots depicting the publication bias of association studies for the ankylosing spondylitis-associated rs30187 single nucleotide polymorphism in the endoplasmic reticulum aminopeptidase 1 gene in (A) combined, (B) Asian and (C) European populations. OR, odds ratio; SE, significant effects.

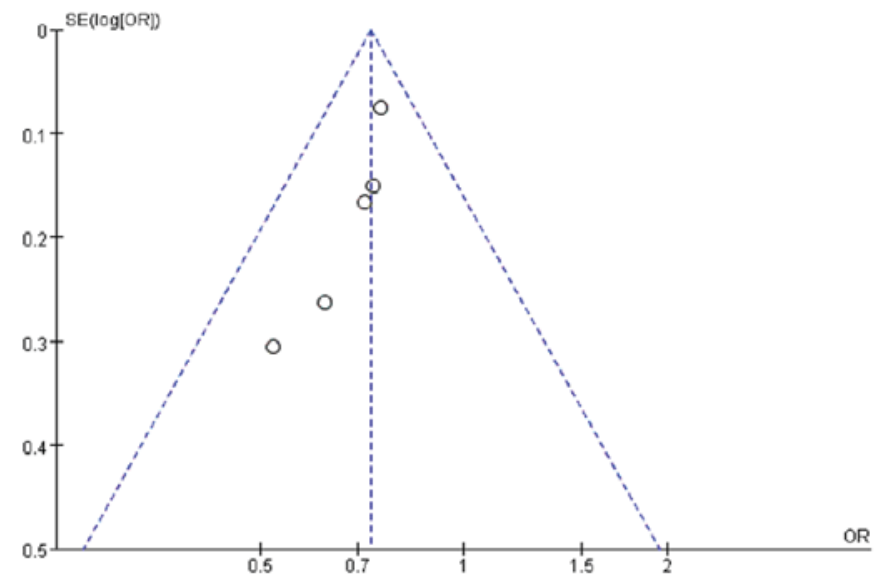

Figure 2. A funnel plot depicting the publication bias of association studies involving the ankylosing spondylitis-associated rs17482078 SNP in the Meta-analysis of the association studies for SNP rs17482078 in the endoplasmic reticulum aminopeptidase 1 gene. OR, odds ratio; SE, significant effects; SNP, single nucleotide polymorphism.

Meta-analysis. A total of 9 studies, which included 7 studies involving subjects of European-descent and two studies involving subject of Asian descent, contributed 4,469 cases and 7,324 controls for the analysis of the association between the ERAP1 SNP rs30187 and AS. Using a random-effects model, a significant difference was identified between the patients and controls for the T-allele of rs30187 (subtotal OR=1.27; $95 \% \mathrm{CI}=1.15-1.40 ; \mathrm{Z}=4.73 ; \mathrm{P}<1.0 \times 10^{-5}$ ) in all of the samples combined, and significant evidence of between-study heterogeneity was identified among the group of allele-wise $\mathrm{ORs}(\mathrm{P}=0.03$; $\mathrm{I}^{2}=54 \%$; Table III). In addition, studies were analyzed separately by ethnicity (European and Asian) to limit the ethnic heterogeneity. The fixed-effects model was used for the European studies $\left(\mathrm{P}=0.53 ; \mathrm{I}^{2}=0 \%\right)$, and the random-effects model was used for the Asian studies $\left(\mathrm{P}=0.004, \mathrm{I}^{2}=82 \%\right)$ according to their heterogeneity tests. A statistically significant summary OR was identified in European studies (subtotal OR=1.29; 95\% CI=1.171.41; $\mathrm{Z}=5.48 ; \mathrm{P}<1.0 \times 10^{-5}$ ) and Asian studies (subtotal $\mathrm{OR}=1.31$; 95\% CI=1.06-1.63; $\mathrm{Z}=2.45 ; \mathrm{P}=0.01$; Table III).

The results of the publication bias tests for the rs30187 SNP are presented in Fig. 1. The results demonstrated that no publication bias existed in this group, as the shapes of the funnel plots did not reveal any obvious asymmetry.
A total of 5 studies involving European populations contributed 1,748 cases and 2,190 controls for the analysis of the association between the ERAP1 SNP rs17482078 and AS. For the T-allele of rs17482078, no significant heterogeneity was detected $\left(\mathrm{P}=0.78 ; \mathrm{I}^{2}=0 \%\right)$. The fixed-effects summary $\mathrm{OR}$ was 0.73 (95\% $\mathrm{CI}=0.65-0.82)$, and a significant association was observed ( $\mathrm{Z}=5.25 ; \mathrm{P}<1.0 \times 10^{-5}$; Table III). There was no evidence of publication bias in these 5 studies (Fig. 2).

Further meta-analyses were performed using the randomeffects or fixed-effects models for rs3734016, rs26653, rs27895, rs2287987, rs27434, rs10050860, rs27044, rs1065407, rs27980, rs7711564 and rs27037 SNPs, according to the results of the heterogeneity test. The summary ORs for 8 SNPs (rs26653, rs2287987, rs27434, rs10050860, rs27044, rs27980, rs7711564 and rs27037) were statistically significant in the combined, European studies and Asian studies (Table IV). There was no evidence of publication bias for these SNPs in their associated studies (data not shown).

Structural and functional analysis. A total of 9 SNPs (rs3734016, rs26653, rs27895, rs2287987, rs27434, rs30187, rs10050860, rs17482078 and rs27044) lead to a genetic variation within the coding region of the ERAPl gene. The PolyPhen-2 software program was used to predict the structural and functional effects of these variations on ERAP1, and the results are presented in Table V. For rs30187 and rs17482078, the results of the functional prediction analysis suggested that these mutations were potentially damaging (scores 0.998 and 0.759 , respectively). No predictions outside of the benign score range were identified for the remaining 6 SNPs (rs3734016, rs26653, rs27895, rs2287987, rs10050860 and rs27044). As the rs27434 SNP generates a synonymous substitution in exon 6, the PolyPhen-2 software was unable to analyze it (Table V).

The crystal structure of ERAP1 revealed four protein domains and a large cavity between domains II and IV (Figs. 3 and 4) (35). Domain I (residues 46-254; brown region, Figs. 4 and 5 ) is an all- $\beta$-sheet domain that docks above the thermolysin domain, caps the active site and provides binding sites for the $\mathrm{N}$-terminus of a substrate peptide. Domain II (residues 255-529; purple region, Figs. 3 and 4) is the catalytic domain that possesses a zinc atom, the exo-peptidase specific G-A-M-E-N motif and the canonical zinc-binding motif (H-E-X-X-H-X $\left.{ }_{18}-\mathrm{E}\right)$ on a thermolysin-like $\alpha \beta$ fold. Domain III (residues 530-614; green region, Figs. 3 and 4) is composed of two $\beta$-sheets that forms a $\beta$-sandwich domain 
Table V. Predicted effects of the identified SNPs on ERAP1 protein function.

\begin{tabular}{lccc}
\hline ERAP1 SNP & $\begin{array}{c}\text { Genomic } \\
\text { coordinates (bp) }\end{array}$ & $\begin{array}{c}\text { Amino acid sequence } \\
\text { alteration or gene location }\end{array}$ & $\begin{array}{c}\text { PolyPhen-2 phenotype } \\
\text { prediction }\end{array}$ \\
\hline rs3734016 & $96,803,761$ & E56K & Benign \\
rs26653 & $96,803,547$ & R127P & Benign \\
rs27895 & $96,793,840$ & G346D & Benign \\
rs2287987 & $96,793,832$ & M349V & Benign \\
rs27434 & $96,793,809$ & A356A & - \\
rs30187 & $96,788,627$ & K528R & 0.000 \\
rs10050860 & $96,786,506$ & D575N & Probably damaging \\
rs17482078 & $96,783,162$ & R725Q & Benign \\
rs27044 & $96,783,148$ & Q730E & Probably damaging \\
rs1065407 & $96,776,379$ & Intron & Benign \\
rs27980 & $96,762,191$ & 3'-UTR & - \\
rs7711564 & $96,760,515$ & Proximal to the 3'-end of ERAP1 & - \\
rs27037 & $96,758,990$ & Proximal to the 3'-end of ERAP1 & 0.998 \\
&
\end{tabular}

SNPs, single nucleotide polymorphisms; ERAP1, endoplasmic reticulum aminopeptidase 1 gene; UTR, untranslated region.
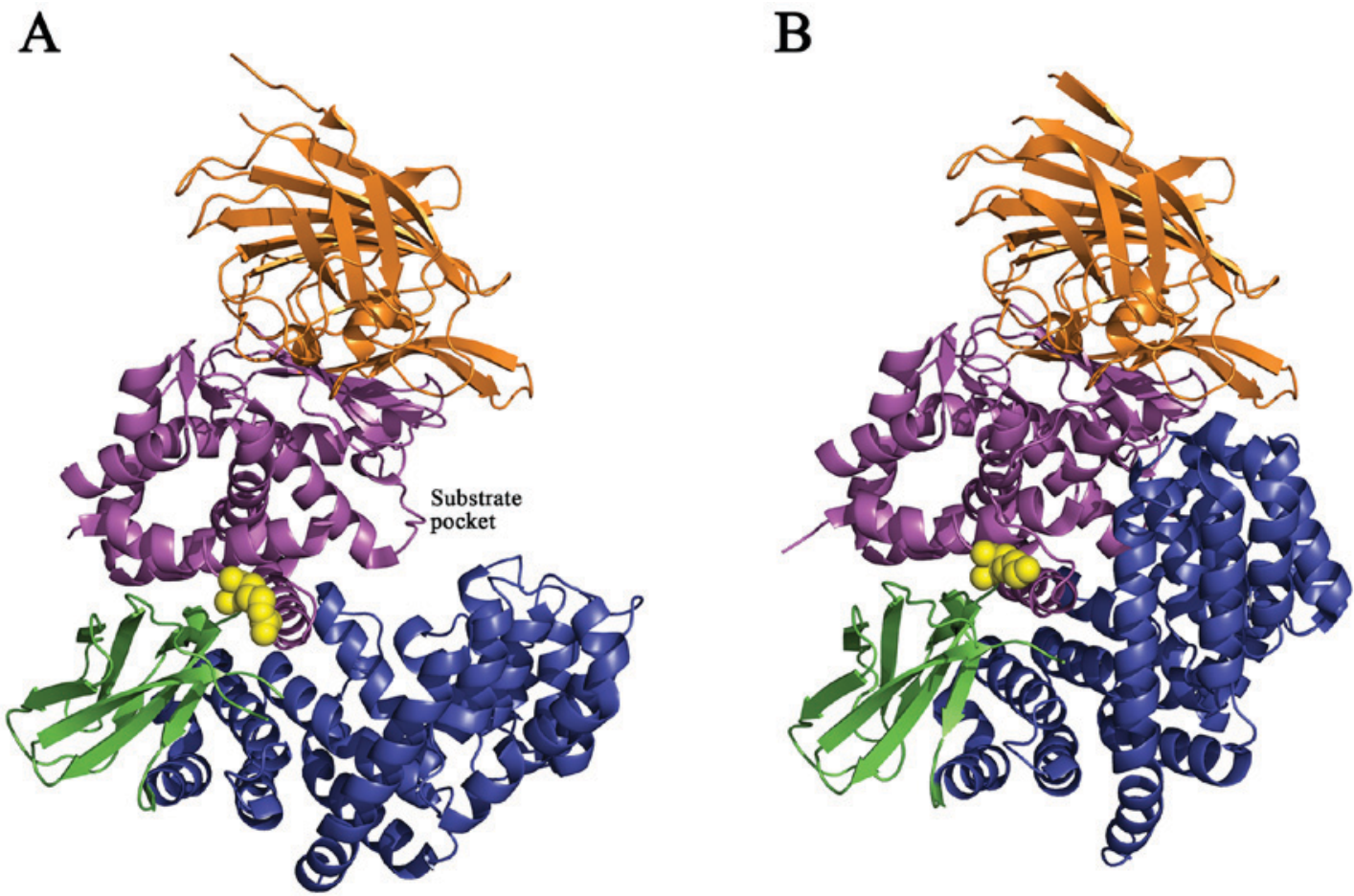

Figure 3. Structure of the human ERAP1 protein and the location of the K528R single nucleotide polymorphism (yellow). (A) Open and (B) closed forms of ERAP1. The four domains of ERAP1 are indicated as follows: Domain I, brown; domain II, purple; domain III, green; domain IV, blue. ERAP1, endoplasmic reticulum aminopeptidase 1 .

between domains II and IV. Domain IV (residues 615-940; blue region, Figs. 3 and 4) consisted solely of $\alpha$-helices and displayed a bowl-like shape. In the closed state, domain IV arches over the catalytic domain and forms a large central cavity that completely obstructs the active site $(35,36)$.

ERAP1 is a multifunctional enzyme involved in cleaving peptides to an optimal length for presentation by MHC class I molecules. The crystal structures of ERAP1 display open and close states, and this enzyme is inactive in its open form (36). The rs30187 SNP (K528R; yellow circles, Fig. 3) is located near the entrance of the substrate pocket and may affect substrate-binding affinity with the enzyme and reduce ERAP1 aminopeptidase activity toward a synthetic peptide substrate (Fig. 3) $(11,37)$. In addition, the rs17482078 SNP (R725Q; red circles, Fig. 4) is located on the inner surface of the C-terminal cavity and may affect the substrate sequence or length specificity (35).

Protein structure prediction analysis provided evidence for the functional role of amino acid residue R725. Two hydrogen bonds were observed to form between R725 and D766 residues with distances of $3.1 \AA$ and $3.2 \AA$ in the closed form of 
A

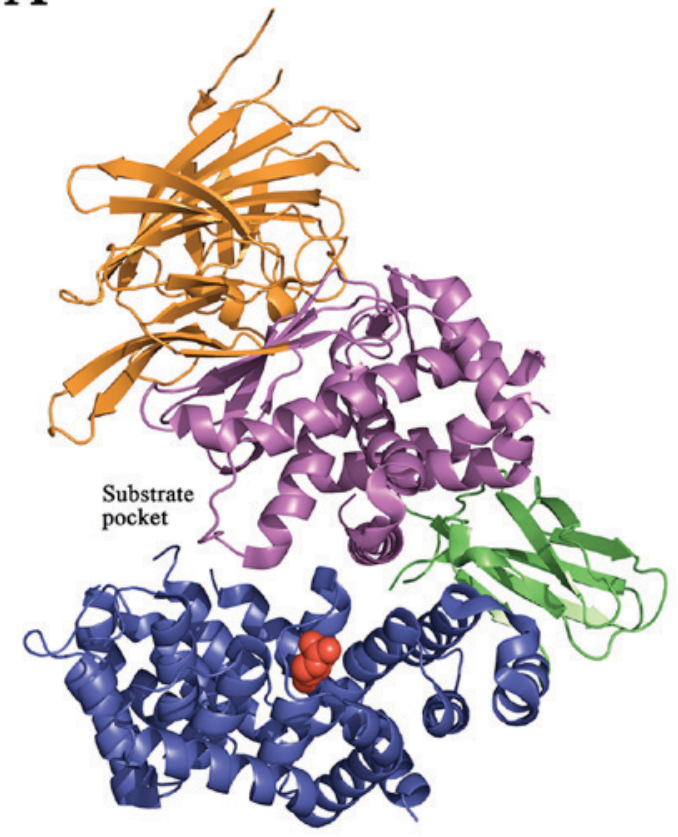

B

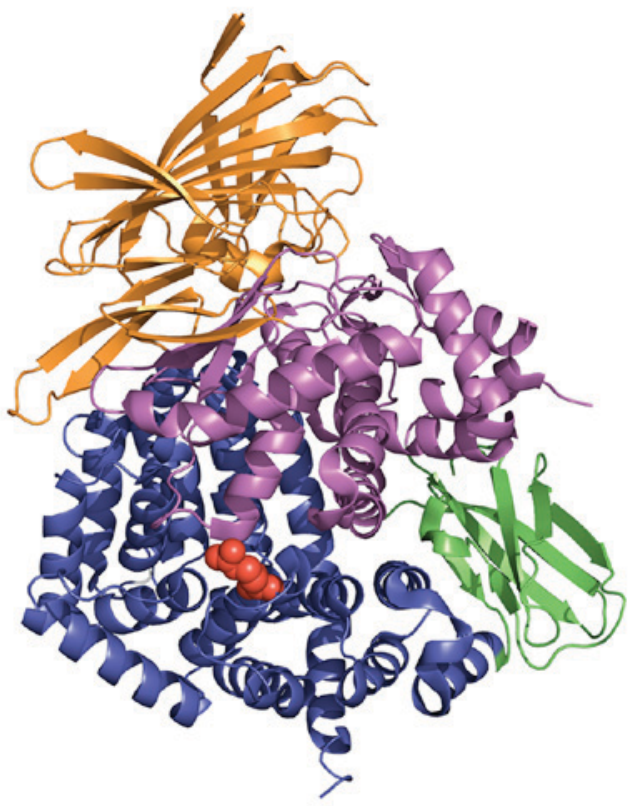

Figure 4. Structure of the human ERAP1 protein and the location of the R725Q single nucleotide polymorphism (red). (A) Open and (B) closed forms of ERAP1. The four domains of ERAP1 are indicated as follows: Domain I, brown; domain II, purple; domain III, green; domain IV, blue. ERAP1, endoplasmic reticulum aminopeptidase 1 .

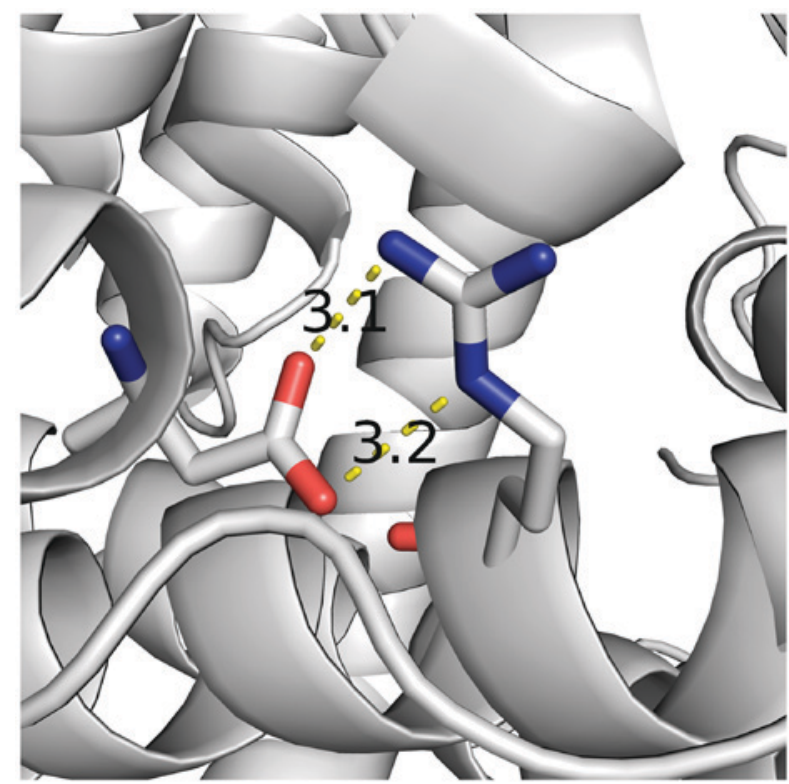

Figure 5. Depiction of two hydrogen bonds between R725 and D766 amino acid residues, with distances of $3.1 \AA$ and $3.2 \AA$, in the closed form endoplasmic reticulum aminopeptidase 1 . The nitrogen atoms are indicated in blue and the oxygen atoms are indicated in red.

ERAP1 (Fig. 5). Based on the aforementioned results and the molecular modeling structure of ERAP1, the R725Q SNP may therefore affect the stability of the C-terminus of ERAP1 in its active state.

\section{Discussion}

In the present study, a two-stage bioinformatic analysis was performed to investigate the association between 13 SNPs in the ERAP1 locus and AS using ethnically diverse independent samples from 14 previously published studies (24). The functional effects of non-synonymous variations were analyzed with protein structure prediction analysis software, and the crystal structure of ERAP1 was examined using the PDB database.

For the rs30187 SNP, the p-value in the combined population was $<0.00001$, suggesting an unequivocal association with AS. When the samples were stratified by ethnicity (European and Asian), the p-values for the association tests for this SNP remained significant $(<0.00001$ and 0.02 , respectively), thus providing additional evidence for the association of this SNP with AS in the two populations (22). For the rs17482078 SNP, a significant association was observed in the European population $(\mathrm{P}<0.00001)$, therefore suggesting an association of this SNP with AS. In addition, 11 additional SNPs (rs3734016, rs26653, rs27895, rs2287987, rs27434, rs10050860, rs27044, rs1065407, rs27980, rs7711564 and rs27037) were investigated to determine their association with AS. The summary ORs for 8 SNPs (rs26653, rs2287987, rs27434, rs10050860, rs27044, rs27980, rs7711564, and rs27037) were statistically significant in the combined, European and Asian studies when using the random-effects or fixed-effects models. However, prior to the meta-analysis, 10 studies investigating ERAPI and AS were excluded from the final statistical analysis due to limited available data. All of the excluded studies also demonstrated significant associations in the above 13 SNPs between the case and control populations (data not shown). These results provided further evidence of an association between ERAPI and AS. Therefore, the results of the present study suggest that ERAPI may be an important susceptibility gene for AS, which is consistent with the results from a number of previously published studies $(1,7,10,12,14,18,20,27,30,32,38-40)$. 
The ERAPI gene is located on chromosome $5 \mathrm{q} 15$ and is translated into two isoforms comprising 941 and 948 amino acids, which are generated via alternative splicing. The active site of ERAP1 spans 375 amino acids (41). Although ERAP1 does not contain any obvious endoplasmic reticulum (ER) retention motifs, as identified in additional ER resident proteins, it is known to localize within the ER; however, exon 10 may serve a role in ER retention (42). ERAP1 is known to have two major functions. Firstly, it is involved in cleaving peptides to the optimal length for MHC class I presentation, and secondly, it cleaves different cell surface cytokine receptors, including tumor necrosis factor receptor 1, interleukin (IL)-1 receptor II and IL-6 receptor $\alpha$ (43).

A previous meta-analysis investigated the potential molecular mechanisms underlying the effect of different genetic variants of ERAP lin the development of AS (40). Goto et al (37) demonstrated that a K528R substitution resulted in reduced ERAP1 enzymatic activity by reducing the hydrolysis of the bioactive hormones, angiotensin II and kallidin $(37,42)$. In addition, these authors identified little difference between the activities of the N575 and E730 mutants when compared with the wild-type (WT), and their results were consistent with the PolyPhen-2 prediction analysis performed in the present study (42). The potentially damaging substitution at R528 (rs30187) has been well documented, and similar results among studies have indicated a 30-40\% reduction in enzymatic activity compared with that of the WT (34-37,44). K528R is located near the entrance of the substrate pocket, and may contribute to substrate-binding affinity, thus leading to reduced ERAP1 aminopeptidase activity with a synthetic peptide substrate (37).

It is hypothesized that Q725 (rs17482078) is an additional potentially damaging substitution, and various in vitro studies have suggested that it decreases the enzymatic activity by $40 \%$ compared with that of the WT $(34,37)$. The protein structure analysis performed in the present study, suggested that this substitution may result the disruption of two hydrogen bonds between R725 and D766 in the active state of ERAP1 and affect the stability of the C-terminus. Based on these alterations, a decrease in the enzymatic activity induced by the substitution of $\mathrm{R}$ to $\mathrm{Q}$ at position 725 may be expected. However, in the present study, the results of the meta-analysis at stage 1 suggested the opposite, as the minor allele of rs17482078 (Q725) was observed to theoretically decrease the risk of AS in the case-control studies involving different populations. Due to the limited understanding of the association between the structure and function of ERAP1, a simple interpretation of the role of rs17482078 is therefore not possible at this stage. Therefore, as further studies emerge, the current findings may be updated and more reliable estimates of the role of this SNP may be obtained.

In conclusion, the results of the two-stage bioinformatics analysis performed in the current study suggested that ERAPI may present an important susceptibility gene for AS, and revealed two functional SNPs (rs30187 and rs17482078) that may decrease the enzymatic activity of ERAP1 by affecting its protein structure. Therefore, future studies investigating the role of these ERAP1 variants in influencing protein structure are warranted.

\section{Acknowledgements}

The authors of the present study are indebted to all of the individuals who have participated in, or helped with, the research. The present study was supported by the National Natural Science Foundation of China (grant nos. 31371298, 81301151 and 81272023), the Program for New Century Excellent Talents in University (grant no. NCET-13-0452) and the Key Project of International Scientific Cooperation of Shaanxi Province (grant no. S2013KW25-02).

\section{References}

1. Lin Z, Bei JX, Shen M, Li Q, Liao Z, Zhang Y, Lv Q, Wei Q, Low HQ, Guo YM, et al: A genome-wide association study in Han Chinese identifies new susceptibility loci for ankylosing spondylitis. Nat Genet 44: 73-77, 2011.

2. Kadi A, Izac B, Said-Nahal R, Leboime A, Van Praet L, de Vlam K, Elewaut D, Chiocchia G and Breban M: Investigating the genetic association between ERAP1 and spondyloarthritis. Ann Rheum Dis 72: 608-613, 2013.

3. Braun J, Bollow M, Remlinger G, Eggens U, Rudwaleit M, Distler A and Sieper J: Prevalence of spondylarthropathies in HLA-B27 positive and negative blood donors. Arthritis Rheum 41: 58-67, 1998.

4. Cai G, Xin L, Wang L, Fan D, Liu L, Hu Y, Ding N, Xu S, Xia G, Jin X, et al: Associations between ERAP1 polymorphisms and ankylosing spondylitis susceptibility: An updated meta-analysis. Mod Rheumatol 25: 453-461, 2015.

5. Brewerton DA, Hart FD, Nicholls A, Caffrey M, James DC and Sturrock RD: Ankylosing spondylitis and HL-A 27. Lancet 1: 904-907, 1973.

6. van der Linden S, Valkenburg H and Cats A: The risk of developing ankylosing spondylitis in HLA-B27 positive individuals: A family and population study. Br J Rheumatol 22 (4 Suppl 2): S18-S19, 1983.

7. Wellcome Trust Case Control Consortium1; Australo-Anglo-American Spondylitis Consortium (TASC), Burton PR, Clayton DG, Cardon LR, Craddock N, Deloukas P, Duncanson A, Kwiatkowski DP, McCarthy MI, et al: Association scan of 14,500 nonsynonymous SNPs in four diseases identifies autoimmunity variants. Nat Genet 39: 1329-1337, 2007.

8. Maksymowych WP, Inman RD, Gladman DD, Reeve JP, Pope A and Rahman P: Association of a specific ERAP1/ARTS1 haplotype with disease susceptibility in ankylosing spondylitis. Arthritis Rheum 60: 1317-1323, 2009.

9. Zvyagin IV, Dorodnykh VY, Mamedov IZ, Staroverov DB, Bochkova AG, Rebrikov DV and Lebedev YB: Association of ERAP1 allelic variants with risk of ankylosing spondylitis. Acta Naturae 2: 72-77, 2010.

10. Pazár B, Sáfrány E, Gergely P, Szántó S, Szekanecz Z and Poór G: Association of ARTS1 gene polymorphisms with ankylosing spondylitis in the Hungarian population: The rs27044 variant is associated with HLA-B*2705 subtype in Hungarian patients with ankylosing spondylitis. J Rheumatol 37: 379-384, 2010.

11. Szczypiorska M, Sánchez A, Bartolomé N, Arteta D, Sanz J, Brito E, Fernández P, Collantes E, Martínez A, Tejedor D, et al: ERAP1 polymorphisms and haplotypes are associated with ankylosing spondylitis susceptibility and functional severity in a Spanish population. Rheumatology (Oxford) 50: 1969-1975, 2011.

12. Bang SY, Kim TH, Lee B, Kwon E, Choi SH, Lee KS, Shim SC, Pope A, Rahman P, Reveille JD and Inman RD: Genetic studies of ankylosing spondylitis in Koreans confirm associations with ERAP1 and 2 p15 reported in white patients. J Rheumatol 38: 322-324, 2011.

13. Mahmoudi M, Jamshidi AR, Amirzargar AA, Farhadi E, Nourijelyani K, Fallahi S, Oraei M, Noori S and Nicknam MH: Association between endoplasmic reticulum aminopeptidase-1 (ERAP-1) and susceptibility to ankylosing spondylitis in Iran. Iran J Allergy Asthma Immunol 11: 294-300, 2012.

14. Chen C and Zhang X: ERAP1 variants are associated with ankylosing spondylitis in East Asian population: A new Chinese case-control study and meta-analysis of published series. Int $\mathbf{J}$ Immunogenet 42: 168-173, 2015. 
15. Wang J, Li H, Wang J and Gao X: Association between ERAP1 gene polymorphisms and ankylosing spondylitis susceptibility in Han population. Int J Clin Exp Pathol 8: 11641-11646, 2015.

16. Wu W, Ding Y, Chen Y, Hua Z, Liu H, Wang H and Jiao G: Susceptibility to ankylosing spondylitis: Evidence for the role of ERAP1, TGFb1 and TLR9 gene polymorphisms. Rheumatol Int 32: 2517-2521, 2012.

17. Cherciu M, Popa LO, Bojinca M, Dutescu MI, Bojinca V, Bara C and Popa OM: Functional variants of ERAP1 gene are associated with HLA-B27 positive spondyloarthritis. Tissue Antigens 82: 192-196, 2013.

18. Cinar M, Akar H, Yilmaz S, Simsek I, Karkucak M, Sagkan RI, Pekel A, Erdem H, Avci IY, Acikel C, et al: A polymorphism in ERAP1 is associated with susceptibility to ankylosing spondylitis in a Turkish population. Rheumatol Int 33: 2851-2858, 2013

19. Zhang Z, Dai D, Yu K, Yuan F, Jin J, Ding L, Hao Y, Liang F, Liu N, Zhao X, et al: Association of HLA-B27 and ERAP1 with ankylosing spondylitis susceptibility in Beijing Han Chinese. Tissue Antigens 83: 324-329, 2014.

20. Davidson SI, Wu X, Liu Y, Wei M, Danoy PA, Thomas G, Cai Q, Sun L, Duncan E, Wang N, et al: Association of ERAP1, but not IL23R, with ankylosing spondylitis in a Han Chinese population. Arthritis Rheum 60: 3263-3268, 2009.

21. Chapman K, Takahashi A, Meulenbelt I, Watson C, Rodriguez-Lopez J, Egli R, Tsezou A, Malizos KN Kloppenburg M, Shi D, et al: A meta-analysis of European and Asian cohorts reveals a global role of a functional SNP in the 5'UTR of GDF5 with osteoarthritis susceptibility. Hum Mol Genet 17: 1497-1504, 2008.

22. Zhang R, Yao J, Xu P, Ji B, Luck JV, Chin B, Lu S, Kelsoe JR and Ma J: A comprehensive meta-analysis of association between genetic variants of GDF5 and osteoarthritis of the knee, hip and hand. Inflamm Res 64: 405-414, 2015.

23. Xu M, St Clair D and He L: Testing for genetic association between the ZDHHC8 gene locus and susceptibility to schizophrenia: An integrated analysis of multiple datasets. Am J Med Genet B Neuropsychiatr Genet 153B: 1266-1275, 2010.

24. Nie F, Wang X, Zhao P, Yang H, Zhu W, Zhao Y, Chen B, Valenzuela RK, Zhang R, Gallitano AL and Ma J: Genetic analysis of SNPs in CACNA1C and ANK3 gene with schizophrenia: A comprehensive meta-analysis. Am J Med Genet B Neuropsychiatr Genet 168: 637-648, 2015.

25. Adzhubei IA, Schmidt S, Peshkin L, Ramensky VE, Gerasimova A, Bork P, Kondrashov AS and Sunyaev SR: A method and server for predicting damaging missense mutations. Nature methods 7: 248-249, 2010

26. Berman HM, Westbrook J, Feng Z, Gilliland G, Bhat TN, Weissig H, Shindyalov IN and Bourne PE: The protein data bank. Nucleic Acids Res 28: 235-242, 2000.

27. Pimentel-Santos FM, Ligeiro D, Matos M, Mourão AF, Sousa E, Pinto P, Ribeiro A, Sousa M, Barcelos A, Godinho F, et al: Association of IL23R and ERAP1 genes with ankylosing spondylitis in a Portuguese population. Clin Exp Rheumatol 27: 800-806, 2009

28. Harvey D, Pointon JJ, Evans DM, Karaderi T, Farrar C, Appleton LH, Sturrock RD, Stone MA, Oppermann U, Brown MA and Wordsworth BP: Investigating the genetic association between ERAP1 and ankylosing spondylitis. Hum Mol Genet 18: 4204-4212, 2009

29. Choi CB, Kim TH, Jun JB, Lee HS, Shim SC, Lee B, Pope A, Uddin M, Rahman P and Inman RD: ARTS1 polymorphisms are associated with ankylosing spondylitis in Koreans. Ann Rheum Dis 69: 582-584, 2010.

30. Australo-Anglo-American Spondyloarthritis Consortium (TASC), Reveille JD, Sims AM, Danoy P, Evans DM, Leo P, Pointon JJ, Jin R, Zhou X, Bradbury LA, et al: Genome-wide association study of ankylosing spondylitis identifies non-MHC susceptibility loci. Nat Genet 42: 123-127, 2010.
31. Li C, Lin Z, Xie Y, Guo Z, Huang J, Wei Q, Li QX, Wang X, Cao $\mathrm{S}$, Liao Z, et al: ERAP1 is associated with ankylosing spondylitis in Han Chinese. J Rheumatol 38: 317-321, 2011.

32. Wang CM, Ho HH, Chang SW, Wu YJ, Lin JC, Chang PY, Wu J and Chen JY: ER AP1 genetic variations associated with HLA-B27 interaction and disease severity of syndesmophytes formation in Taiwanese ankylosing spondylitis. Arthritis Res Ther 14: R125, 2012.

33. Liu Y, Li L, Shi S, Chen X, Gao J, Zhu M and Yuan J: Association study of ankylosing spondylitis and polymorphisms in ERAP1 gene in Zhejiang Han Chinese population. Rheumatol Int 36: 243-248, 2016.

34. Evans DM, Spencer CC, Pointon JJ, Su Z, Harvey D, Kochan G, Oppermann U, Dilthey A, Pirinen M, Stone MA, et al: Interaction between ERAP1 and HLA-B27 in ankylosing spondylitis implicates peptide handling in the mechanism for HLA-B27 in disease susceptibility. Nat Genet 43: 761-767, 2011.

35. Nguyen TT, Chang SC, Evnouchidou I, York IA, Zikos C, Rock KL, Goldberg AL, Stratikos E and Stern LJ: Structural basis for antigenic peptide precursor processing by the endoplasmic reticulum aminopeptidase ERAP1. Nat Struct Mol Biol 18: 604-613, 2011.

36. Kochan G, Krojer T, Harvey D, Fischer R, Chen L, Vollmar M, von Delft F, Kavanagh KL, Brown MA, Bowness P, et al: Crystal structures of the endoplasmic reticulum aminopeptidase-1 (ERAP1) reveal the molecular basis for $\mathrm{N}$-terminal peptide trimming. Proc Natl Acad Sci USA 108: 7745-7750, 2011.

37. Goto $Y$,Hattori A, Ishii $Y$ and Tsujimoto $M$ : Reduced activity of the hypertension-associated Lys528Arg mutant of human adipocytederived leucine aminopeptidase (A-LAP)/ER-aminopeptidase-1. FEBS Lett 580: 1833-1838, 2006.

38. Robinson PC and Brown MA: Genetics of ankylosing spondylitis. Mol Immunol 57: 2-11, 2014.

39. Lee YH, Choi SJ, Ji JD and Song GG: Associations between ERAP1 polymorphisms and ankylosing spondylitis susceptibility: A meta-analysis. Inflamm Res 60: 999-1003, 2011.

40. Chen R, Yao L, Meng T and Xu W: The association between seven ERAP1 polymorphisms and ankylosing spondylitis susceptibility: A meta-analysis involving 8,530 cases and 12,449 controls. Rheumatol Int 32: 909-914, 2012.

41. Yousaf N, Low WY, Onipinla A, Mein C, Caulfield M, Munroe PB and Chernajovsky Y: Differences between disease-associated endoplasmic reticulum aminopeptidase 1 (ERAP1) isoforms in cellular expression, interactions with tumour necrosis factor receptor 1 (TNF-R1) and regulation by cytokines. Clin Exp Immunol 180: 289-304, 2015.

42. Reeves E, Elliott T, James E and Edwards CJ: ERAP1 in the pathogenesis of ankylosing spondylitis. Immunol Res 60: 257-269, 2014

43. Haroon N: Endoplasmic reticulum aminopeptidase 1 and interleukin-23 receptor in ankylosing spondylitis. Curr Rheumatol Rep 14: 383-389, 2012.

44. Evnouchidou I, Kamal RP, Seregin SS, Goto Y, Tsujimoto M, Hattori A, Voulgari PV, Drosos AA, Amalfitano A, York IA and Stratikos E: Cutting Edge: Coding single nucleotide polymorphisms of endoplasmic reticulum aminopeptidase 1 can affect antigenic peptide generation in vitro by influencing basic enzymatic properties of the enzyme. J Immunol 186: 1909-1913, 2011. 